\title{
Impact of Bullying and Low Perceived Social Support on Ultra- High-Risk for Psychosis in Immigrant Adolescents: A Preliminary Study
}

\author{
Anna Riva ${ }^{1}$, Monica Bomba ${ }^{1}$, Elisa Maserati ${ }^{1}$, Francesca Neri ${ }^{2}$ Renata Nacinovich ${ }^{2}$ \\ ${ }^{1}$ Child and Adolescent Mental Health Department, San Gerardo Hospital, ASST Monza, Italy \\ ${ }^{2}$ Child and Adolescent Mental Health Department, San Gerardo Hospital, ASST Monza, School of Medicine and \\ Surgery, University of Milan Bicocca, Italy \\ Correspondence: Anna Riva, MD, Child and Adolescent Mental Health Department, San Gerardo Hospital, ASST \\ Monza, Via Pergolesi, 33, 20900 Monza, Italy.
}

Received: August 21, 2017

doi:10.11114/ijsss.v5i11.2605
Accepted: September 19, $2017 \quad$ Available online: October 13, 2017

URL: https://doi.org/10.11114/ijsss.v5i11.2605

\begin{abstract}
The purpose of our research is to identify, in a sample of immigrant adolescents, the presence of Ultra-High-Risk (UHR) for psychosis and to analyze the interaction between UHR, experience of bullying victimization and low social support. Data were collected from the medical records of 31 immigrant adolescents. CAARMS (Comprehensive Assessment of At-Risk Mental States) was used to determine the presence of ultra high risk (UHR) of developing psychosis, while MSPSS (Multidimensional Scale of Perceived Social Support) for the perceived social support. $45.2 \%$ of subjects resulted at high risk for psychosis (UHR). In the UHR group the $57.1 \%$ of the subjects told to be victims of bullying ( $p$ $=0,007)$. The MSPSS outlined that $17.2 \%$ of the subjects declared that they received a low social support, the $58.6 \%$ average, and the $24.1 \%$ a high support. Significant differences between UHR and NOT UHR group considering a low perceived social support emerged. Considering the fixed variable "being or not being bullied", a direct correlation between bullying $(\rho=0.431)$ and UHR and an indirect correlation between the MSPSS total score $(\rho=-0.273)$ and UHR emerged. Results of the multiple linear regression considering UHR as a dependent variable confirmed that both the variables are significant $(\mathrm{p}=0.0082)$ and that they both contribute to the risk of psychosis. Preliminary results of our study suggest a relevant and causal relation between bullying, low social support and psychosis in immigrant adolescents.
\end{abstract}

Keywords: adolescent, immigrant, bullying, psychosis, social support

\section{Introduction}

The psychopathological risk for mental health in immigrants is subject of interest and study by beginning of last century (Kraepelin, 1904). The literature reports recurrence in this population of various disorders as depression / withdrawal (Levecque , Lodewyckx \&\& Vranken ,2007 ), aggressive / deviant behavior (Stevens \& Vollebergh, 2008), Psychosomatic disorders (Sundquist, Bayard-Burfield, Johansson, \& Johansson, 2000; Gruner, Oster , Müller , \& von Wietersheim , 2012), school failure (Georgiades, Boyle, \& Fife, 2013), psychotic break (Veling 2013), self-harm and suicidality ( Kim \& Leventhal, 2008), psychosis (Cantor-Graae, \& Selten, 2005). The impact of psychotic disorders in the general adult population is 0.5-5 / 10,000 and the odds ratio for the risk of psychosis in immigrant adults is 2.9 compared to the general population (Cantor-Graae, \& Selten, 2005). When we say that adults experience psychotic-like effects as a consequence of migration, we mean the sudden outburst of persecutory delirium with emphasis on perceived discrimination in subjects with no history of psychosis and no show of other positive psychotic symptoms (Nelson, Fusar-Poli, \& Yung, 2012). Being able to recognize an UHR for psychosis in immigrant adolescents is therefore useful to implement preventive interventions and reduce the risk of developing psychosis in adulthood.

Recognized risk factors for the development of psychosis in immigrants are: immigration occurred in developmental age, i.e. childhood or adolescence (Veling \& Susser, 2011; Bomba, Riva, Capelli, Neri, \& Nacinovich, 2017), separation or loss of parents or relatives (Morgan et al., 2007; Bourque, van der Ven, Fusar-Poli, \& Malla, 2012), perceived discrimination (Berg et. al, 2011), poor social support (Hefner \& Heisenberg, 2009; Tonsing, Zimet, \& Tse, 2012) and 
bullying (Vieno, Santinello, Lenzi, Baldassari,\& Mirandola, 2009).

Many studies confirmed the association between childhood adversity (sexual abuse, physical abuse, emotional/psychological abuse, neglect, parental death, and bullying), the onset of psychotic disorders (Varese F, Smeets F, Drukker M, Lieverse R, Lataster T, Viechtbauer W, Read J, van Os J, Bentall RP., 2012) and their persistence (Trotta A, Murray RM, Fisher HL, 2015).

Bullying is a serious issue that causes a wide range of short and long-term psychological problems in children who are victims of it (Rettew DC, Pawlowski S., 2016), but its consequences in immigrant adolescents are still poorly studied. To our knowledge, only one previously published research described an increased risk to experience bullying victimization in immigrant adolescents than natives native-born youth. Furthermore, immigrant youth who experienced bullying victimization were more likely to report interpersonal, socio-emotional, health, and substance abuse problems (Maynard, Vaughn, Salas-Wright, \& Vaughn, 2016).

The purpose of our study is to identify, in a clinical sample of immigrant adolescents, the presence of Ultra-High-Risk traits for psychosis (UHR) and then to analyze the relevance and the interaction between UHR and experience of bullying victimization and low social support. In this manuscript, the preliminary data of the study on a sample of 31 adolescents are described.

\section{Method}

\subsection{Participants}

Data were collected from the medical records of 50 immigrant adolescents, inpatients and outpatients at the Child and Adolescent Mental Health Department -S. Gerardo Hospital, ASST Monza - University of Milano Bicocca (Milano, Italy) between January 2016 and June 2016. The purpose of the study was adequately communicated to both participants and their parents and a written informed consent to participate was obtained. The research was reviewed and approved by the institutional review board of S. Gerardo Hospital -ASST Monza.

We included in our sample only subjects with a psychiatric diagnosis and at least one foreign-born parent. 15 subjects with a neurological diagnosis or a history of adoption or fostering and 4 subjects with missed information in the medical records were excluded from the analysis.

The final sample is constituted of 31 immigrant adolescents (mean age: 14.74 years, SD 1.39), 20 females (64,5\%) and 11 males (35,5\%). 14 adolescents (45.2\%) were first-generation subjects, $17(54.8 \%)$ second generation ones and / or children of mixed couples. In medical history 10 subjects (32.3\%) told to be victims of bullying. Country of origin of parents' sample group are summarized in Figure 1.

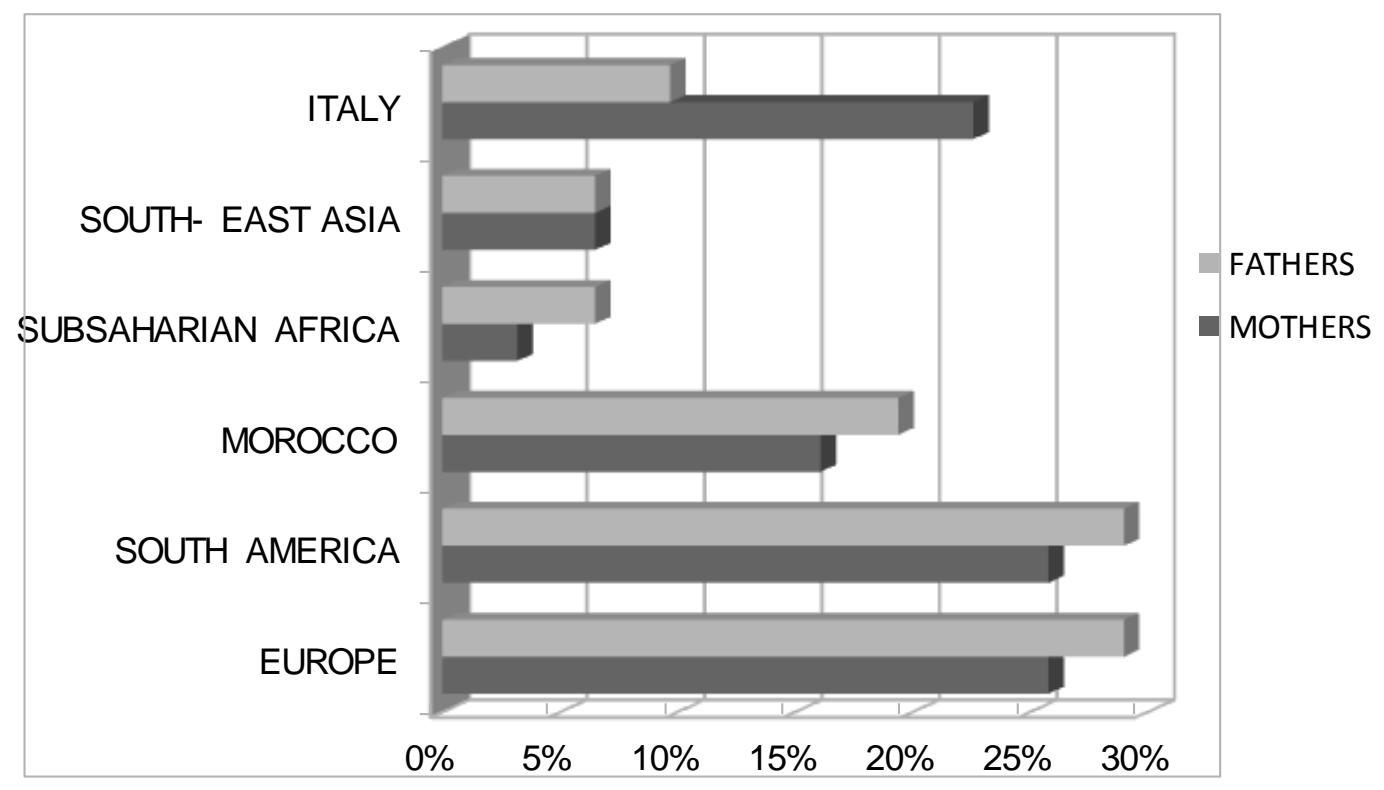

Figure 1. Country of origin of parents' sample group 


\subsection{Measures}

\subsubsection{Comprehensive Assessment of At Risk Mental States (CAARMS)}

The CAARMS is a semi-structured interview that has two functions: (i) to assess psychopathology thought to indicate imminent development of a first-episode psychotic disorder; and (ii) to determine if an individual meets criteria for being at ultra high risk (UHR) for onset of first psychotic disorder (Yung, Phillips, Yuen, \& McGorry, 2006). In our research we used the Italian Version of the test (Fusar-Poli, Hobson, Raduelli \& Balottin U, 2012).

\subsubsection{Multidimensional Scale of Perceived Social Support Assessment (MSPSS)}

The MSPSS (Zimet, Dahlem, Zimet \& Farley 1988) is a scale consisting of 12 items which identify three specific dimensions, each composed of 4 item (Family, Friends, Significant Others), for the evaluation of the subjective perception of social support received. Each dimension measure both the global support and the emotional support received by each subject. The 12-items are evaluated through a Likert scale with a score from 1 ( "very much disagree") to 7 ( "very much agree"); the final score is obtained by calculating the total average (MSPSS TOT) of 12 items, and the average of the scores divided into 3 dimensions, Family (MSPSS_FAM), friends (MSPSS_FRI), and other significant (MSPSS_SO). The total average (MSPSS TOT) describes the social support perceived by the subject into three categories: high, moderate, low.

\subsection{Statistical Analysis}

Continuous variables were expressed as mean and standard deviation (SD) and they were analyzed through the ANOVA test. Categorical variables are reported as percentages of the total number. For the categorical variables a descriptive analysis of the distributions was carried out by means of contingency tables and the p-value of frequencies comparison was evaluated through Pearson Chi-square test. Multiple linear regression analysis was performed to evaluate the influence of more dependent variables on an independent variable. Simple logistic regressions were used to explore associations between variables and outcomes. The significance level was set at $\mathrm{p}<0.05$. Statistical analysis was performed using the SPSS 20.0 package.

\section{Results}

Results at CAARMS are summarized in Table 1.

Table 1. Results at CAARMS and history of bullying in UHR vs Not UHR patients

\begin{tabular}{llll}
\hline & UHR & NOT UHR & ${\text { TOT }\left(\mathrm{N}^{\mathrm{a}}\right)}$ \\
& $\mathrm{N}^{\mathrm{a}}(\%)$ & $\mathrm{N}^{\mathrm{a}}(\%)$ & 31 \\
\hline CAARMS & $14(45.2 \%)$ & $17(54,8)$ & \\
Attenuated form of psychosis & 11 & & 10 \\
Vulnerability & 3 & $2(11,4 \%)$ & 10 \\
BULLYING VICTIM & $8(57,1 \%)$ & & \\
\hline
\end{tabular}

${ }^{\mathrm{a}} \mathrm{N}=$ numbers; UHR=Ultra High Risk for Psychosis

14 subjects (45.2\%) result at high risk for psychosis (Ultra High Risk, UHR), and in particular 11 (35.9\%) at the time of the evaluation have an attenuated form of psychosis and $3(9.7 \%)$ a vulnerability to psychosis. The remaining 17 subjects (54.8\%), do not present at the time of the evaluation criteria for an increased risk of developing psychosis. Comparing the two groups (UHR and not UHR) in relation to the age, the typology of immigration and the countries of origin no significant differences emerged. Amongst the observed variables, in the subgroup UHR the $57.1 \%$ of the subjects have a positive anamnesis for being victims of bullying, while only the $11.8 \%$ of not-UHR subgroup. This difference observed in the two subgroups is statistically significant $(\mathrm{p}=0,007)$. These results means that the $80 \%$ of subjects of the sample that were bullying victim belong to the UHR subgroup.

The MSPSS, filled out by all the participants, outlined that $17.2 \%$ of the subjects declared that they received a low social support, the $58.6 \%$ an average support, and $24.1 \%$ a high social support.

The analysis of variance (ANOVA, see Table 2) was used to determine statistical differences between the two subgroups (UHR vs NOT UHR), considering the scores obtained in the MSPSS tests. 
Table 2. Differences between the two subgroups (UHR vs NOT UHR) in MSPSS scales

\begin{tabular}{|c|c|c|c|}
\hline & UHR (mean, S.D. ${ }^{d}$ ) & NOT UHR (mean, S.D.) & p-value \\
\hline MSPSS_Pt ${ }^{a}$ & $53,62(12,61)$ & $63,06(9,01)$ & 0,026 \\
\hline MSPSSpz_FAM $^{\mathrm{b}}$ & $17,38(8,57)$ & $22,50(5,12)$ & 0,057 \\
\hline MSPSSpz_FRI $^{\mathrm{c}}$ & $14,94(8,93)$ & $20,75(5,66)$ & 0,042 \\
\hline \multicolumn{4}{|c|}{$\begin{array}{l}\text { a MSPSSpt = patients' social support perceived Total score; }{ }^{\mathrm{b}} \text { MSPSSpt_FAM }=\text { patients' social support perceived from } \\
\text { Family; }{ }^{\mathrm{c}} \text { MSPSSpt_FRI= patients' social support perceived from Friends. }{ }^{\mathrm{d}} \text { S.D.: standard deviation }\end{array}$} \\
\hline \multicolumn{4}{|c|}{$\begin{array}{l}\text { Statistically significant differences between UHR and NOT UHR group considering low perceived social support } \\
\text { (MSPSS TOTAL scale } \mathrm{p}=0,026 \text {; MSPSS_FRIENDS p 0.042; MSPSS_FAMILY } \mathrm{p}=0.057 \text { ) emerged. }\end{array}$} \\
\hline \multirow{2}{*}{\multicolumn{4}{|c|}{$\begin{array}{l}\text { A fixed variable "bullying victim or not bullying vic } \\
\text { the Spearman nonparametric test. The results show } \\
\text { risk of psychosis and an indirect correlation between } \\
\text { were used as independent variables in a multiple line } \\
\text { Table 3. Multiple Linear Regression in UHR group }\end{array}$}} \\
\hline & & & \\
\hline & Coefficient & $\mathrm{SE}^{\mathrm{b}}$ & p-value \\
\hline & 0.980 & 0.472 & 0.047 \\
\hline MSPSSpt $^{\mathrm{a}}$ & -0.011 & 0.007 & 0.144 \\
\hline Bullying victim & 0.444 & 0.175 & 0.017 \\
\hline
\end{tabular}

${ }^{a}$ MSPSSpt $=$ patients' social support perceived Total score. bSE:=standard error.

The analysis confirmed that both the variables are statistically significant ( $\mathrm{R}$ square $=0.29, \mathrm{p}$ value $=0.0082$ ) and that they contribute, with a prevalence of the variable "bullying victim", to the prediction of the risk of psychosis.

\section{Discussion}

The preliminary data of our work suggest a strong connection between bullying victimization, low social support and psychosis in a sample of immigrant children. To our knowledge, this is the first study conducted on a clinical sample that investigates, in immigrant adolescents, relations between these three aspects.

In our study, the $45.2 \%$ of the sample results at high risk for psychosis and the $57.1 \%$ of these subjects have a positive anamnesis for being victims of bullying.

Immigrants, proper of their condition of immigration, are often marginalized and discriminated and in consequence of this, have a higher risk to become victims of bullying (Maynard, Vaughn, Salas-Wright, \&Vaughn, 2016). Despite these considerations, results of researches that have investigated relations between immigration status and bullying victimization are controversial. In fact if some researches describe that immigrant youths are more likely to be bullied than native-peers (Bjereld Y, Daneback,\& Petzold, 2015; Maynard, Vaughn, Salas-Wright, \& Vaughn, 2016 ), others researches do not confirm these data (McKenne, Pepler, Craig, \& Connolly, 2006). However Maynard et at. (2016), in their study on a large population of School-Aged Children, also indicate that immigrant youth who experience bullying victimization were more likely to report interpersonal, socio-emotional, health and substance use problems.

When not focusing on immigrant children, scientific literature mostly agrees in considering bullying as one of the most relevant factor in childhood and adolescence for the development of emotional and behavioral problems as anxiety and depression (Moore et al, 2017) and for an increased risk of suicides (Kim YS \& Le venthal B., 2008). Furthermore, in recent years, studies outlined also the relationship between childhood adversity (included bullying victimization) and the onset of psychotic symptoms in children and adolescents ( Horrevorts, Monshouwer, Wigman, \& Vollerbergh, 2014; Lindgren, 2017). Such relationship, as outlined in the introduction, is quite relevant in the immigrant population considering that they have an increased risk to develop psychosis than non-immigrants.

When focusing on the perceived social support, the statistically significant differences between ultra-high risk and not ultra-high risk group can be interpreted as showing that the condition of being ultra-high risk for psychosis correlates to lower perceived social supports. This hypothesis is confirmed by data of literature that recognize the role of social support in improving the outcome of psychotic symptoms in adolescents (Wang L, Shi J, Chen F, Yao Y, Zhan C, Yin X, Fang X, Wang H, Yuan J, Zhao X., 2015). 
Finally results of the multiple linear regression considering ultra-high risk for psychosis as a dependent variable showed that both the variables (bullying and low social support) are statistically significant and that they both contribute, with a prevalence of the variable "bullying victim", to the prediction of the risk of psychosis in our clinical sample of immigrant adolescents.

\section{Conclusions}

The originality of our study is to have analyzed, in a clinical sample of immigrant adolescents, how bullying victimization and low social support together contribute in developing UHR for psychosis. These results, if confirmed in further analysis in a larger sample and in comparison to a control group of native-peers, need to be taken into strong consideration for risk assessment procedures and prevention based policies directed towards population.

\section{Declaration of Interest}

The authors declare that they have no conflict of interest.

\section{Acknowledgements}

Many thanks to all the children and the families who accepted to participate in our study. We also acknowledge the colleagues of the ASST of Monza for their contribution to the enrollment.

\section{References}

Berg, A. O., Melle, I., Rossberg, J. I., Romm, K. L., Larsson, S., Lagerberg, T. V., \& Andreassen, O. A. (2011). Hauff. Perceived discrimination is associated with severity of potive and depression /anxiety symptoms in immigrants with psychosis: a cross-sectional study. Bio Med Central Psychiatry, 11, 77. https://doi.org/10.1186/1471-244X-11-77

Bjereld, Y., Daneback, K., \& Petzold, M. (2015). Differences in prevalence of bullying victimization between native and immigrant children in the Nordic countries: a parent-reported serial cross-sectional study. Child Care Health Dev., 41(4), 593-599. https://doi.org/10.1111/cch.12184

Bomba, M., Riva, A., Capelli, M., Neri, F., \& Nacinovich, R. (2017). Migratory processes and psychiatric disorders in a sample of adolescents: a retrospective observational study. Cogent Psychol, 4. https://doi.org/10.1080/23311908.2017.1320081

Bourque, F., van der Ven, E., \& Fusar-Poli, P. (2012). Malla A. Immigration, social environment and onset of psychotic disorders. Curr Pharm Des., 18(4), 518-526. https://doi.org/10.2174/138161212799316028

Cantor - Graae E., \& Selten, J. P. (2005). Schizophrenia and Migration: AMeta- Analysis and Review. American Journal of Psychiatry, 162, 12-24. https://doi.org/10.1176/appi.ajp.162.1.12

Fusar-Poli, P., Hobson, R., Raduelli, M., \& Balottin, U. (2012). Reliability and validity of the Comprehensive Assessment of the At Risk Mental State, Italian version (CAARMS-I). Curr Pharm Des., 18(4), 386-391. https://doi.org/10.2174/138161212799316118

Georgiades, K., Boyle, M. H., \& Fife, K. A. (2013). Emotional and behavioral problems among adolescent students: the role of immigrant, racial/ethnic congruence and belongingness in schools. Journal of Youth and Adolescence, 42(9), 1474-1492. https://doi.org/10.1007/s10964-012-9868-2

Gruner, A., Oster, J., Müller, G., \& von Wietersheim, J. (2012). Symptoms, disease models and treatment experiences of patients in psychosomatic rehabilitation with and without a history of migration. Z Psychosom Med Psychother, 58(4), 385-393. https://doi.org/10.13109/zptm.2012.58.4.385

Hefner, J., \& Eisenberg, D. (2009). Social Support and Mental Health Among College Students. American Journal of Orthopsychiatry. American Psychological Association, 79(4), 491-499. https://doi.org/10.1037/a0016918

Horrevorts, E. M. B., Monshouwer, K., Wigman, J. T. W., \& Vollerbergh, W. A. M. (2014). The relation between bullying and subclinical psychotic experiences and the influence of the climate of school classes. European Child and Adolescent Psychiatry, 23, 765-772. https://doi.org/10.1007/s00787-014-0524-0

Kim, Y. S., \& Le venthal, B. (2008). Bullying and suicide. Areview. International Journal of Adolescent Medical Health, 20(2), 133-154. https://doi.org/10.1515/IJAMH.2008.20.2.133

Kraepelin, E. (1904). Comparative psychiatry. In Cultural psychiatry and Medical Anthropology: an introduction and reader (ed. R. Littlewood and S. Dein) pagg.38-42. Atlon Press, London.

Levecque, K., Lodewyckx, I., \& Vranken, J. (2007). Depression and generalised anxiety in the general population in Belgium: a comparison between native and immigrant groups. $J$ Affect Disord, 97(1-3), 229-239. https://doi.org/10.1016/j.jad.2006.06.022 
Lindgren, M., Mäntylä, T., Rikandi, E., Torniainen-Holm, M., Morales-Muñoz, I., Kieseppä, T., ... Suvisaari, J. (2017). Childhood adversities and clinical symptomatology in first-episode psychosis. Psychiatry Res., pii.

Maynard, B. R., Vaughn, M. G., Salas-Wright, C. P., \& Vaughn, S. (2016). Bullying Victimization Among School-Aged Immigrant Youth in the United States. $J$ Adolesc Health, 58(3), 337-344. https://doi.org/10.1016/j.jadohealth.2015.11.013

McKenney, K. S., Pepler, D., Craig, W., \& Connolly, J. (2006). Peer victimization and psychosocial adjustment: The experiences of Canadian immigrant youth. Electron J Res Ed Psychol, 9, 239-264.

Moore, S. E., Norman, R. E., Suetani, S. Thomas, H. J., Sly, P. D., \& Scott, J. G. (2017). Consequences of bullying victimization in childhood and adolescence: Asystematic review and meta-analysis. World J Psychiatry, 7(1), 60-76. https://doi.org/10.5498/wjp.v7.i1.60

Morgan, C., Kirkbride, J., Leff, J., Craig, T., Hutchinson, G., McKenzie, K., ... Fearon, P. (2007). Parental separation, loss and psychosis in different ethnic groups: a case -control study. Psychological Medicine, 37, 495-503. https://doi.org/10.1017/S0033291706009330

Nelson, B., Fusar-Poli, P., Yung, A. R. (2012). Can we detect psychotic-like experiences in the general population? Curr Pharm Des., 18(4), 376-385. https://doi.org/10.2174/138161212799316136

Rettew, D. C., \& Pawlowski, S. (2016). Bullying. Child Adolesc Psychiatr Clin N Am., 25(2), 235-242. https://doi.org/10.1016/j.chc.2015.12.002

Stevens, G., \& Vollebergh, W. (2008). Mental health in migrant children. The Journal of Child Psychology and Psychiatry, 49(3), 276-294. https://doi.org/10.1111/j.1469-7610.2007.01848.x

Sundquist, J., Bayard-Burfield, L., Johansson, L. M., \& Johansson, S. E. (2000). Impact of ethnicity, violence and acculturation on displaced migrants: psychological distress and psychosomatic complaints among refugees in Sweden. J Nerv Ment Dis., 188(6), 357-365. https://doi.org/10.1097/00005053-200006000-00006

Tonsing, K., Zimet, G. D., \& Tse, S. (2012). Assessing social support among South Asians: The multidimensional scale of perceived social support. Asian J Psychiatr, 5(2), 164-168. https://doi.org/10.1016/j.ajp.2012.02.012

Trotta, A., Murray, R. M., \& Fisher, H. L. (2015). The impact of childhood adversity on the persistence of psychotic symptoms: a systematic review and meta-analysis. Psychol Med., 45(12), 2481-2498. https://doi.org/10.1017/S0033291715000574

Varese, F., Smeets, F., Drukker, M., Lieverse, R., Lataster, T., Viechtbauer, W., ... Bentall, R. P. (2012). Childhood adversities increase the risk of psychosis: a meta-analysis of patient-control, prospective- and cross-sectional cohort studies. Schizophr Bull., 38(4), 661-671. https://doi.org/10.1093/schbul/sbs050

Veling, W., \& Susser, E. (2011). Migration and psychotic disorders. Expert Review of Neurotherapeutics, 11(1), 65-76. https://doi.org/10.1586/ern.10.91

Veling, W. (2013). Ethnic minority position and risk for psychotic disorders. Current opinion in psychiatry, 26(2), 166-171. https://doi.org/10.1097/YCO.0b013e32835d9e43

Vieno, A., Santinello, M., Lenzi, M., Baldassari, D., \& Mirandola, M. (2009). Health Status in Immigrants and Native Early Adolescents in Italy. Journal of Community Health, 34, 181-187. https://doi.org/10.1007/s 10900-008-9144-2

Wang, L., Shi, J., Chen, F., Yao, Y., Zhan, C., Yin, X., ... Zhao, X. (2015). Family Perception and 6-Month Symptomatic and Functioning Outcomes in Young Adolescents at Clinical High Risk for Psychosis in a General Population in China. PLoS One., 10(9). https://doi.org/10.1371/journal.pone.0138361

Yung, A. R., Phillips, L. J., Yuen, H. P., \& McGorry, P. D. (2006). Comprehensive Assessment of at Risk Mental State, The PACE Clinic, ORYGEN Research Centre, University of Melbourne, Department of Psychiatry, Parkville, Australia.

Zimet, G. D., Dahlem, N. W., Zimet, S. G., \& Farley, G. K. (1988). The Multidimensional Scale of Percieved Social Support. Journal of Personality Assessment, 52,30-41. https://doi.org/10.1207/s15327752jpa5201_2

\section{Copyrights}

Copyright for this article is retained by the author(s), with first publication rights granted to the journal.

This is an open-access article distributed under the terms and conditions of the Creative Commons Attribution license which permits unrestricted use, distribution, and reproduction in any medium, provided the original work is properly cited. 